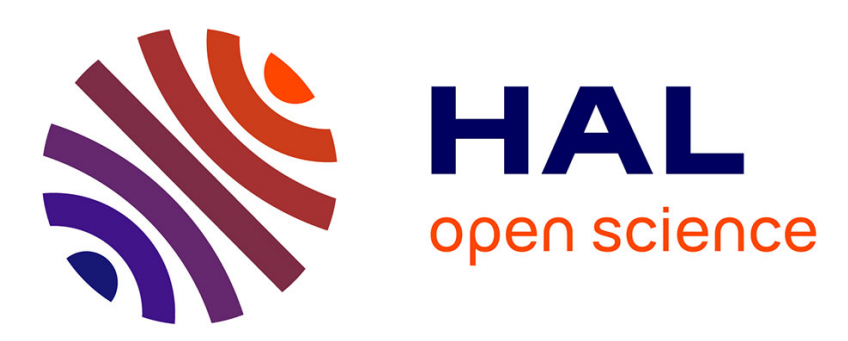

\title{
New electrophysiological mapping combined with MRI in parkinsonian's subthalamic region
}

Jerome Coste, Lemlih Ouchchane, Laurent Sarry, Philippe Derost, Franck Durif, Jean Gabrillargues, Simone Hemm, Jean-Jacques Lemaire

\section{To cite this version:}

Jerome Coste, Lemlih Ouchchane, Laurent Sarry, Philippe Derost, Franck Durif, et al.. New electrophysiological mapping combined with MRI in parkinsonian's subthalamic region. European Journal of Neuroscience, 2009, 29 (8), pp.1627-1633. 10.1111/j.1460-9568.2009.06698.x . hal-01544654

\author{
HAL Id: hal-01544654 \\ https://hal.science/hal-01544654
}

Submitted on 21 Jun 2017

HAL is a multi-disciplinary open access archive for the deposit and dissemination of scientific research documents, whether they are published or not. The documents may come from teaching and research institutions in France or abroad, or from public or private research centers.
L'archive ouverte pluridisciplinaire HAL, est destinée au dépôt et à la diffusion de documents scientifiques de niveau recherche, publiés ou non, émanant des établissements d'enseignement et de recherche français ou étrangers, des laboratoires publics ou privés. 


\title{
$\underline{\text { New Electrophysiologic Mapping Combined with MRI in Parkinsonian's }}$
}

\section{subthalamic region}

\author{
$\mathrm{J} \mathrm{Coste}^{(1,2)} ;$ L Ouchchane ${ }^{(2,3)} ;$ L Sarry ${ }^{(2)} ; \mathrm{P}^{\text {Derost }^{(4)}}$; \\ F Durif $^{(4)}$; J Gabrillargues ${ }^{(5)}$; S Hemm ${ }^{(2)}$, JJ Lemaire ${ }^{(1,2)}$
}

${ }^{1}$ CHU Clermont-Ferrand, Hôpital Gabriel Montpied, Service de Neurochirurgie A, ClermontFerrand, F-63003 France.

${ }^{2}$ Univ Clermont 1, UFR Médecine, EA3295, Equipe de Recherche en signal et Imagerie Médicale, Clermont-Ferrand, F-63001 France.

3 CHU Clermont-Ferrand, Hôpital Gabriel Montpied, Laboratoire de Biostatistiques, Télématique et Traitement d'Images, Clermont-Ferrand, F-63003 France.

${ }^{4}$ CHU Clermont-Ferrand, Hôpital Gabriel Montpied, Service de Neurologie, Clermont-Ferrand, F-63003 France.

${ }^{5}$ CHU Clermont-Ferrand, Hôpital Gabriel Montpied, Service de Radiologie A, ClermontFerrand, F-63003 France.

\section{Corresponding author:}

Jérôme Coste

Service de Neurochirurgie A, Hôpital Gabriel Montpied

B.P. 69, 63003 Clermont-Ferrand cedex 1, FRANCE.

Fax +33(0) 473752166

Email: jcoste@chu-clermontferrand.fr

Running head: Electrophysiological mapping and MRI anatomy.

Keywords: Subthalamic nucleus, electrophysiology, spontaneous activity, deep brain stimulation, Parkinson's disease.

21 pages, 3 figures and 2 tables; Words: i 5342, ii 225/250, iii 435/500 


\begin{abstract}
The subthalamic nucleus (STN) is the main target for deep brain stimulation in Parkinson's disease. We analyzed the relationships between MRI anatomy and spontaneous neuronal activity to confirm the potential of microelectrode recordings to assist in determining the optimal surgical target.
\end{abstract}

Ten bilateral surgeries were performed after 1.5-T (T2-weighted) anatomical MRI identification of the STN, zona incerta (ZI), Forel's field H2 and substantia nigra (SN). Spontaneous neuronal activity was recorded simultaneously along the distal $10 \mathrm{~mm}$ on a central track (optimally covering the STN) and a $2 \mathrm{~mm}$ anterior track. We calculated off line mean firing rate and burst frequency on 248 neurons clustered according to anatomic structure. Subjective visual analysis of signal was also realized on line, during surgery, to classify patterns of activity.

Mean firing rate and burst frequency increased from H2-ZI to SN. Mean firing rate was higher in STN only using paired comparison (STN versus its neighbours). Burst frequency was lower in $\mathrm{H} 2$ than in $\mathrm{SN}$; using comparison with neighbours, it was lower in $\mathrm{H} 2$ and ZI. An irregular high activity (type 2C) was more often detected in STN and SN than in H2 and ZI.

Anatomical boundaries and unitary recordings appear to be linked, supporting the ability of MRI to provide a detailed anatomy. Electrophysiological mapping combined with MRI is a useful tool for precise targeting in the subthalamic region. 


\section{Introduction}

Bilateral chronic high-frequency subthalamic nucleus (STN) stimulation, or STN deep brain stimulation (DBS), is widely accepted as a valuable treatment for alleviating motor complications in advanced Parkinson's disease (Pollak et al., 1993; Benabid et al., 1994; Krack et al., 1997; Kumar et al., 1998; Benabid et al., 2000; Lang, 2000; Rodriguez-Oroz et al., 2004; Liang et al., 2006). The STN is most often localized by classical indirect procedures based on probabilistic stereotactic atlases (Talairach et al., 1957; Schaltenbrand \& Bailey, 1959) or graphs (Benabid et al., 2002), given a position relative to the anterior and posterior commissure (AC-PC) line, defined by contrast ventriculography, computerized tomography (CT) or magnetic resonance imaging (MRI). The STN can also be directly visualized on T2-weighted MRI sequences. New MRI sequences increasing the visibility of the STN region have made direct patient-by-patient anatomic mapping using 1.5-Tesla images the option of choice (Lemaire et al., 1999; Coubes et al., 2002; Plaha et al., 2006; Derost et al., 2007; Lemaire et al., 2007a; Lemaire et al., 2007b; Hemm et al., 2008). In our institution, the DBS electrodes are guided stereotactically (Lemaire et al., 2007b) by: 1) preoperative primary targeting of the anatomic region where the DBS electrode is to be placed, based on direct precise anatomic MRI mapping of relevant structures (nuclei and bundles) with true 3D planning of trajectories; 2) intraoperative secondary targeting of the optimal physiological position along the preoperatively-defined trajectories, based on microelectrode recordings and micro stimulation assessments. Intra operative secondary targeting classically employs neurophysiologic and clinical monitoring techniques to fine-tune the primary targeting (Hutchison et al., 1998; Limousin et al., 1998) in order to determine the location of the "target" along the planned (intended) trajectories or to indicate where new trajectories have to be followed. Different electrode systems are used to precisely characterize the STN and its 
boundaries before positioning the DBS electrode, as reviewed by Gross et al. The physiological characteristics of the STN, including neuron firing rate and patterns, and the neighbouring structures enables positive identification of the so-called electrophysiological target (Gross et al., 2006). Thus, the classic electrophysiological approach in stereotactic surgery aims to pinpoint an electrophysiological signature (activity) that is, a priori pathognomonic for a specific nucleus, and this signature is often taken as representative of the best area to place the electrode contact(s) (Table1).

We aimed to study electrophysiological neuronal activity in a new way, according to different subthalamic structures precisely defined on anatomic MRI. We hypothesised that the combination of new systematic electrophysiological mapping with detailed MRI anatomy should allow to explore finely anatomo-electrophysiologic relationships and also to determine precisely functional surgical targets. 


\section{Material and methods}

\section{Patients}

Ten patients, suffering from severe Parkinson's disease, were included on the condition that the electrophysiological recordings displayed a good signal-to-noise ratio: $60 \pm 8$ years old (mean \pm SD), 7 males and 3 females, with 10 \pm 4 years of disease duration; the pre-operative UPDRS motor score was $35.4 \pm 4.0$ and 8.2 \pm 5.7 , respectively without and with L-dopa. They all fulfilled criteria for a DBS procedure according to the guidelines of the French Health Agency. Clinical, MRI and electrophysiological data were analyzed prospectively included after Institutional Review Board (University Hospital of Clermont-Ferrand, Clermont-Ferrand, France) approval. Post operative controls (6 months) showed a dramatic improvement of motor control (part III of UPDRS) with a mean improvement of $63.6 \%$ ( \pm 6.0 ; ranging from 25.6 to 83.9 ).

\section{Surgical procedure}

Stereotactic frame (Leksell G frame, Elekta, Sweden) was placed using the repositioning kit (Leksell repositioning kit, Elekta, Sweden) under local anaesthesia, without stopping antiparkinson drug therapy. Stereotactic MRI (Sonata 1.5 Tesla, Siemens, Germany) was performed with a voxel size of $0.52 \times 0.62 \times 2 \mathrm{~mm} 3(\mathrm{FOV}=270 \mathrm{~mm}$; matrix $=512 \times 435$, slice thickness $=2 \mathrm{~mm}$ ). T2-weighted sequences were run to visualize both the stereotactic markers and the subthalamic anatomy of the nuclei and bundles (Lemaire et al., 2007b). For the purposes of patient comfort, the frame was removed during the planning phase that used stereotactic software (Iplan, BrainLab, Germany). We identified (labelled) and manually outlined the main structures of the subthalamic region (Figure 1A): STN, zona incerta (ZI), substantia nigra (SN), red nucleus $(\mathrm{RN})$, nucleus of the ansa lenticularis (nAL), the fields of Forel (H1 or thalamic 
fasciculus, $\mathrm{H} 2$ or lenticular fasciculus). Labelling was performed based on surgical anatomic knowledge and in-house 3D 4.7-Tesla MRI anatomy software (Lemaire et al., 2004). The two trajectories (right and left) were planned as follows: 1) double obliquity (ring and arc angles), $2^{\text {nd }}$ frontal gyrus entrance point, extra-ventricular trajectory, avoidance of vessels and caudate nucleus; 2) optimization in order to explore the STN from its superior and lateral border (Figure 1A). We planned an exploration (electrophysiological recordings and stimulation tests) from the ventral thalamus to the medial $\mathrm{SN}$, along the distal $10 \mathrm{~mm}$ of the track. The following day, the frame was repositioned under local anaesthesia and in antiparkinson drug free conditions. Intraoperative X-rays controls were conducted throughout the procedure to check that the tracks followed the planning. The whole procedure was realized with extreme caution in order to minimize brain shift secondary to cerebro-spinal fluid leakage (patient in recumbent position plus "closed dura mater" approach with water/airtight guide tubes; Bengun, Immi, France). Two quadripolar electrodes (DBS 3389, Medtronic, USA) were placed during the same procedure. For each DBS electrode (right and left) we optimized the positioning of one contact (contact 1), as we usually use monopolar stimulation. For each side, the implantation was realized after electrophysiological mapping using an intraoperative electrophysiological system for functional neurosurgery (MicroGuide, Alpha Omega Eng., Israel; (Slavin \& Burchiel, 2002)). For each hemisphere, the mapping was performed using two exploration electrodes (Alpha Omega Eng., Israel) steered by rigid guide tubes: one on the planned track (named the central track) and a second one on the parallel track located anteriorly at $2 \mathrm{~mm}$ (named the anterior track).

The characteristics of our electrophysiological approach were as follows: systematic recordings of the spontaneous neuronal activity every $0.5 \mathrm{~mm}$ during 30 seconds along the distal $10-\mathrm{mm}$ course of the exploration electrodes, regardless of signal-to-noise ratio or pattern of activity. This 
electrophysiological mapping step lasted 20 minutes per side and data were saved for off-line analysis.

We first recorded extracellular neuronal activity (mean duration per record $\cong 30 \mathrm{sec}$ ) every 500 $\mu \mathrm{m}$ (with the tip of the electrode: diameter $=25 \mu \mathrm{m}$, length $=100 \mu \mathrm{m}$ ) followed by acute stimulation tests (up to $4 \mathrm{~mA}$; after retraction of the recording tip, with the stimulation zone: diameter $=550 \mu \mathrm{m}$, length $=1.2 \mathrm{~mm}$, surface $\cong 2.1 \mathrm{~mm}^{2}$ ) every $1 \mathrm{~mm}$. The centre of contact 1 of the DBS electrode was placed on the track where we found the best stimulation parameters. This optimization was based solely on stimulation effects. Mean duration of the whole bilateral implantation procedure was 7 hours. Postoperative radiographic controls were performed to check that the intended trajectories had been realized, by matching preoperative (MRI), intraoperative (X-rays) and postoperative (X-Rays and/or MRI) image sets matching (stereotactic matching and/or mutual information algorithm; Iplan, BrainLab, Germany).

\section{Electrophysiologic data}

Electrophysiological data were theoretically available for a total of 840 recordings corresponding to 40 tracks (10 patients $\times 2$ sides $\times 2$ tracks); this dataset exhibited a hierarchical structure with 21 checkpoints nested in each track and tracks nested in each hemisphere, with each patient obviously providing two sets of data. The recordings were first classified on-line, intraoperatively (electrophysiologist and neurosurgeon), blind to the anatomical data: (i) visual evaluation of 30second consecutive and spontaneous cell activity replayed on a 5-second frame display (MicroGuide, Alpha Omega Eng., Israel); according to six patterns, regardless of signal amplitude (Figure 1B). We defined pattern rate as the number of recordings of one particular pattern in a specific structure divided by the total number of recordings in the structure and in its 
neighbours; hence, one pattern rate was defined for each of the six types of patterns, and this for each structure. The signal was also analyzed off-line (Alpha Omega Studio, Alpha Omega Eng., Israel). Detected spikes were classified using principal component projection. Burst detection was run using the max-interval algorithm and the surprise method (Legendy \& Salcman, 1985). Mean firing rate $(\mathrm{Hz})$ and burst frequency (burst/min) were calculated.

\section{Merging electrophysiological data with the anatomical MRI space}

The electrophysiological data were merged with the anatomical structures as follows: each recording checkpoint was attributed to one structure according to its position along the track explored (from $-10 \mathrm{~mm}$ to $0 \mathrm{~mm}$ ).

\section{Statistical analysis}

We searched for links between anatomy and electrophysiology. Anatomy was accounted as categorical variable, each structure being one category. Electrophysiological data generated several continuous parameters: mean firing rate, burst frequency and pattern rates, this latter resulting from visual patterns of neuronal activity. For each parameter, we performed paired means comparison between the structure and the structure's neighbours: H2 versus ZI, STN plus H1; ZI versus $\mathrm{H} 1, \mathrm{H} 2$ plus STN; STN versus nAL, ZI, H2 plus SN; SN versus STN. This analysis was carried-out testing towards 0 the mean difference between these two measures (structure value minus neighbour value) through a signed-ranks test. This difference was computed to shorten display and interpretation, a positive result meaning the structure had a higher activity than its neighbours. 
In addition, for each electrophysiological parameter, structure values were compared between structures through mixed linear regression and, when appropriate, all pairwise differences were tested with adjusted p-values (Kramer, 1956).

All statistical analyses were performed on SAS v9.1 (SAS Institute Inc., Cary, NC, USA) using two-tailed formulation with a type I error set to 0.05 .

\section{Results}

\section{Relationship between anatomy and spontaneous electrophysiological activity (mean firing rate and burst frequency)}

Seven hundred ninety eight checkpoints were available (out of 840; data from one hemisphere in one patient were unreadable). A total of 248 neurons were clustered according to anatomic structure. The structures most frequently encountered along the tracks were STN $(n=116)$, SN $(n=45), Z I$ ( $n=43), H 2(n=37)$. The mean firing rate and burst frequency of structures, as well as the differences between structure and neighbours, are displayed Table 2.

Mean firing rates (mean $\pm \mathrm{SD} ; \mathrm{Hz}$ ) were not significantly different: the null hypothesis of no difference between them was not rejected $\left(F_{3,24}=2.13, \mathrm{P}=0.1227\right.$; Figure $2 \mathrm{~A}$ and Table 2$)$. For the burst frequency (burst/min) we found that $\mathrm{H} 2$ was significantly different from $\mathrm{SN}(P=0$. 0403) (Figure 2B and Table 2): the null hypothesis of no difference between them was rejected $\left(F_{3,24}=3.13, P=0.0443\right)$.

Using comparison between structure and neighbours, there was no significant difference regarding mean firing rate, but for $\mathrm{SN}$ where it was higher (Table 2); for the burst frequency, a significant difference was found for $\mathrm{H} 2(-0.32 \pm 0.14, P=0.0078)$ and $\mathrm{ZI}(-0.31 \pm 0.45, P=0.0195)$ (Table 2). 


\section{Relationship between anatomy and pattern rate}

Analyses were restricted to the most encountered types of patterns (1, 2A, 2B, 2C and 4). Only the irregular high activity (2C) pattern rate (PR) was significantly different (Figure 2C and Table 2) and this for certain structures: (i) H2's PR was lower than STN's $(P=0.0200)$ and SN's $(P=$ 0. 0412), the null hypothesis of no difference was rejected $\left(\mathrm{F}_{3,26}=4.99, \mathrm{P}=0.0073\right)$; (ii) $\mathrm{H} 2$ 's and ZI's were different from PRs of their neighbours, paired comparison testing towards 0 the difference, respectively, $-0.15 \pm 0.14, P=0.0273$ and $-0.11 \pm 0.15, P=0.0371$ ).

\section{Discussion}

We recorded and analyzed spontaneous neuronal activity in the subthalamic regions of Parkinsonian patients during DBS electrode implantation. Off-line analysis showed a progressive increase in neuronal activity from the $\mathrm{ZI} / \mathrm{H} 2$ to $\mathrm{SN}$ regions.

The mean firing rate is higher in STN only when compared with neighbours (Table 2). The burst frequency is lower in $\mathrm{H} 2$ than in $\mathrm{SN}$ (Figure 2B); using comparison with neighbours, it was lower in $\mathrm{H} 2$ and $\mathrm{ZI}$ (Table 2).

It is noticeable that these results were obtained according to detailed anatomical analysis of stereotactic MRI, done preoperatively, hence blind to the electrophysiological signal; even the subjective on line visual analysis of recordings was blind to the anatomy. This consolidates the pertinence of MRI anatomic information already studied in our group (Lemaire et al, 2007b) and the anatomo-electrophysiological relationships observed in this study.

Mean firing rate measured in the STN was $20 \pm 14 \mathrm{~Hz}$. This STN mean firing rate appears low compared to most of previously reported data (Table 1). However, all these studies employed 
approaches that were basically different from our method: indeed, we did not isolate neurons or exclude low signal-to-noise ratio but we systematically moved the electrodes in at half-millimetre increment steps. Systematic recording is not the same approach as isolation of neurons, and since our approach did not optimize signal-to-noise ratio, we may have lost part of the signal.

Another difference lies in choice of trajectories. The distal end of our direct patient-by-patient anatomic trajectories is relatively more medial than when using the classic probabilistic atlas approach (Figure 3). Hence, mean firing rates reported by other studies likely refer to the lateral SN corresponding mainly to the pars reticulata, whereas medially we mostly reached the pars compacta, which in Parkinson's disease is characterized by loss of dopamine neurons. However, very little is known about this sub-part in humans, which may explain our low activity recorded for SN.

Nevertheless, our method was able to differentiate the STN from the neighbouring structures in terms of mean firing rate or burst frequency. These parameters are not easily accessible during the surgery due to the post-processing workload required. Consequently, we have developed a visual approach of pattern classification, regardless of signal amplitude (Figure 1B). These patterns could not be directly attributed to anatomical structures. Nevertheless, analysis of the visual evaluations of pattern of activities revealed that pattern with irregular high activity (2C) could be used to discriminate $\mathrm{H} 2$ from adjacent structures, particularly the STN and SN.

Prompted by the fact that little is known about the correlation between the position of the STN as seen on 1.5-T MRI (stereotactic axial T2; $2 \mathrm{~mm}$ slice thickness) and the position determined by microelectrode recording (MER) mapping, (Hamani et al., 2005) compared MRI STN anatomy and MER in 10 Parkinsonian patients. Their electrophysiological characterization of the STN was based on increases in background activity and the presence of movement-related cells when entering the STN, and decreases in neuronal activity when leaving the STN and before entering 
the SN. They concluded that there was a good fit between these two localization methods, with discrepancies mostly inferior to $1 \mathrm{~mm}$.

Another team proposed an objective approach using spike frequency, cell burst index, signalrelative root mean square and spike-relative amplitude correlated with electrode depth to determine a quality index (QI) for each track (Pralong et al., 2004). For each individual track, four regression lines were computed: frequency versus depth, cell burst index versus depth, signal-relative root mean square versus depth and spike-relative amplitude versus depth. The QI for any given track was computed as the average of the slope angle differences between regression lines using all the neurons. Their index was correlated with post-operative measurement of electrode length in the STN, thereby demonstrating the correlation of electrophysiology mapping with imaging mapping. They did not analyze clinical outcome.

In our study, we found good relationships between MRI anatomy and spontaneous electrophysiological recordings in the subthalamic region during stereotactic surgery for severe idiopathic Parkinson's disease: mean firing rate measurements combined with patterns analysis showed significantly lower activity in ZI and H2, then a first increase of neuronal activity when entering the STN and a second increase when reaching the SN. Nevertheless, it is not easy to distinguish between STN and SN based solely on visual signal classification, except for the pattern with irregular high activity (2C) which was significantly lower in $\mathrm{H} 2$ and $\mathrm{ZI}$ than in neighbouring structures. Burst frequency analysis appeared to complement mean firing rate measurements in discriminating the different structures, particularly with an increase of both in the STN then another increase in the SN. In another study, it has been reported that mean firing rate and burst index analysis were able to precisely determine the vertical position of the STN (Pralong et al., 2002). 
We routinely used this systematic recording of spontaneous neuronal activity every $0.5 \mathrm{~mm}$ combined with on-line visual classification approach during DBS surgery to build an electrophysiological mapping consolidating MRI anatomy. These electrophysiological data coupled with MRI anatomy could be integrated in the future for the analysis of postoperative clinical effects by matching multiple data (Lemaire et al., 2007a) identifying the pertinent parameters would make it possible to determine, intra operatively and on-line, the optimal electrophysiological site for electrode contact positioning.

\section{Abbreviations}

DBS: deep brain stimulation

H2: Forel's field H2

SN: substantia nigra

STN: subthalamic nucleus

ZI: zona incerta

\section{References}

Bejjani BP, Dormont D, Pidoux B, Yelnik J, Damier P, Arnulf I, Bonnet AM, Marsault C, Agid Y, Philippon J, \& Cornu P (2000). Bilateral subthalamic stimulation for Parkinson's disease by using three-dimensional stereotactic magnetic resonance imaging and electrophysiological guidance. J Neurosurg 92, 615-625.

Benabid AL, Koudsie A, Benazzouz A, Fraix V, Ashraf A, Le Bas JF, Chabardes S, \& Pollak P (2000). Subthalamic stimulation for Parkinson's disease. Arch Med Res 31, 282-289.

Benabid AL, Koudsie A, Benazzouz A, Le Bas JF, \& Pollak P (2002). Imaging of subthalamic nucleus and ventralis intermedius of the thalamus. Mov Disord 17 Suppl 3, S123-S129. 
Benabid AL, Pollak P, Gross C, Hoffmann D, Benazzouz A, Gao DM, Laurent A, Gentil M, \& Perret J (1994). Acute and long-term effects of subthalamic nucleus stimulation in Parkinson's disease. Stereotact Funct Neurosurg 62, 76-84.

Benazzouz A, Breit S, Koudsie A, Pollak P, Krack P, \& Benabid AL (2002). Intraoperative microrecordings of the subthalamic nucleus in Parkinson's disease. Mov Disord 17 Suppl 3, S145-S149.

Coubes P, Vayssiere N, El Fertit H, Hemm S, Cif L, Kienlen J, Bonafe A, \& Frerebeau P (2002). Deep brain stimulation for dystonia. Surgical technique. Stereotact Funct Neurosurg 78, 183-191.

Derost PP, Ouchchane L, Morand D, Ulla M, Llorca PM, Barget M, Debilly B, Lemaire JJ, \& Durif F (2007). Is DBS-STN appropriate to treat severe Parkinson disease in an elderly population? Neurology 68, 1345-1355.

Galati S, Mazzone P, Fedele E, Pisani A, Peppe A, Pierantozzi M, Brusa L, Tropepi D, Moschella V, Raiteri M, Stanzione P, Bernardi G, \& Stefani A (2006). Biochemical and electrophysiological changes of substantia nigra pars reticulata driven by subthalamic stimulation in patients with Parkinson's disease. European Journal of Neuroscience 23 , 2923-2928.

Gross RE, Krack P, Rodriguez-Oroz MC, Rezai AR, \& Benabid AL (2006). Electrophysiological mapping for the implantation of deep brain stimulators for Parkinson's disease and tremor. Mov Disord 21, S259-S283.

Hamani C, Richter EO, Andrade-Souza Y, Hutchison W, Saint-Cyr JA, \& Lozano AM (2005). Correspondence of microelectrode mapping with magnetic resonance imaging for subthalamic nucleus procedures. Surg Neurol 63, 249-253.

Hemm S, Caire F, Coste J, Vassal F, Nuti C, Derost P, Ouchchane L, Sarry L, Durif F, \& Lemaire JJ (2008). Postoperative Control in Deep Brain Stimulation of the Subthalamic Region: The Contact Membership Concept. International Journal of Computer Assisted Radiology and Surgery 3, 69-77.

Hutchison WD, Allan RJ, Opitz H, Levy R, Dostrovsky JO, Lang AE, \& Lozano AM (1998). Neurophysiological identification of the subthalamic nucleus in surgery for Parkinson's disease. Ann Neurol 44, 622-628.

Krack P, Limousin P, Benabid AL, \& Pollak P (1997). Chronic stimulation of subthalamic nucleus improves levodopa-induced dyskinesias in Parkinson's disease. Lancet 350, 1676. 
Kramer CY (1956), "Extension of Multiple Range Tests to Group Means with Unequal Numbers of Replications," Biometrics 12, 309-310.

Kumar R, Lozano AM, Kim YJ, Hutchison WD, Sime E, Halket E, \& Lang AE (1998). Doubleblind evaluation of subthalamic nucleus deep brain stimulation in advanced Parkinson's disease. Neurology 51, 850-855.

Lang AE (2000). Surgery for Parkinson disease: A critical evaluation of the state of the art. Arch Neurol 57, 1118-1125.

Legendy CR \& Salcman M (1985). Bursts and recurrences of bursts in the spike trains of spontaneously active striate cortex neurons. J Neurophysiol 53, 926-939.

Lemaire JJ, Caire F, Bonny JM, Kemeny JL, Villéger A, \& Chazal J (2004). Contribution of 4.7Tesla MRI in the analysis of the MRI anatomy of the human subthalamic area. Acta Neurochir (Wien ) 146, 906-907.

Lemaire JJ, Coste J, Ouchchane L, Caire F, Nuti C, Derost P, Cristini V, Gabrillargues J, Hemm S, Durif F, \& Chazal J (2007a). Brain mapping in stereotactic surgery: A brief overview from the probabilistic targeting to the patient-based anatomic mapping. Neuroimage 37, S109-S115.

Lemaire JJ, Coste J, Ouchchane L, Hemm S, Derost P, Ulla M, Siadoux S, Gabrillargues J, Durif F, \& Chazal J (2007b). MRI anatomical mapping and direct stereotactic targeting in the subthalamic region: functional and anatomical correspondence in Parkinson's disease. International Journal of Computer Assisted Radiology and Surgery 2, 75-85.

Lemaire JJ, Durif F, Boire JY, Debilly B, Irthum B, \& Chazal J (1999). Direct stereotactic MRI location in the globus pallidus for chronic stimulation in Parkinson's disease. Acta Neurochir (Wien ) 141, 759-765.

Levy R, Hutchison WD, Lozano AM, \& Dostrovsky JO (2000). High-frequency synchronization of neuronal activity in the subthalamic nucleus of parkinsonian patients with limb tremor. $J$ Neurosci 20, 7766-7775.

Liang GS, Chou KL, Baltuch GH, Jaggi JL, Loveland-Jones C, Leng L, Maccarone H, Hurtig HI, Colcher A, Stern MB, Kleiner-Fisman G, Simuni T, \& Siderowf AD (2006). Long-term outcomes of bilateral subthalamic nucleus stimulation in patients with advanced Parkinson's disease. Stereotact Funct Neurosurg 84, 221-227. 
Limousin P, Krack P, Pollak P, Benazzouz A, Ardouin C, Hoffmann D, \& Benabid AL (1998). Electrical stimulation of the subthalamic nucleus in advanced Parkinson's disease. $N$ Engl J Med 339, 1105-1111.

Magarinos-Ascone CM, Figueiras-Mendez R, Riva-Meana C, \& Cordoba-Fernandez A (2000). Subthalamic neuron activity related to tremor and movement in Parkinson's disease. Eur $J$ Neurosci 12, 2597-2607.

Magnin M, Morel A, \& Jeanmonod D (2000). Single-unit analysis of the pallidum, thalamus and subthalamic nucleus in parkinsonian patients. Neuroscience 96, 549-564.

Maltete D, Jodoin N, Karachi C, Houeto JL, Navarro S, Cornu P, Agid Y, \& Welter ML (2007). Subthalamic stimulation and neuronal activity in the substantia nigra in Parkinson's disease. $J$ Neurophysiol 97, 4017-4022.

Merello M, Tenca E, \& Cerquetti D (2006). Neuronal activity of the zona incerta in Parkinson's disease patients. Mov Disord 21, 937-943.

Montgomery EB, Jr. (2007). Subthalamic nucleus neuronal activity in Parkinson's disease and epilepsy subjects. Parkinsonism Relat Disord.

Parent A \& Carpenter M.B. (1996). Carpenter's Human Neuroanatomy, 9th ed., pp. -1011. Lippincott Williams \& Wilkins, Baltimore, Philadelphia, Hong Kong, London, Munich, Sydney, Tokyo.

Plaha P, Ben Shlomo Y, Patel NK, \& Gill SS (2006). Stimulation of the caudal zona incerta is superior to stimulation of the subthalamic nucleus in improving contralateral parkinsonism. Brain 129, $1732-1747$.

Pollak P, Benabid AL, Gross C, Gao DM, Laurent A, Benazzouz A, Hoffmann D, Gentil M, \& Perret J (1993). [Effects of the stimulation of the subthalamic nucleus in Parkinson disease]. Rev Neurol (Paris) 149, 175-176.

Pralong E, Ghika J, Temperli P, Pollo C, Vingerhoets F, \& Villemure JG (2002). Electrophysiological localization of the subthalamic nucleus in parkinsonian patients. Neurosci Lett 325 , 144-146.

Pralong E, Villemure JG, Bloch J, Pollo C, Daniels RT, Ghika J, Vingerhoets F, Tetreault MH, \& Debatisse D (2004). Quality index for the quantification of the information recorded along 
standard microelectrode tracks to the subthalamic nucleus in parkinsonian patients. Neurophysiol Clin 34, 209-215.

Rodriguez-Oroz MC, Rodriguez M, Guridi J, Mewes K, Chockkman V, Vitek J, DeLong MR, \& Obeso JA (2001). The subthalamic nucleus in Parkinson's disease: somatotopic organization and physiological characteristics. Brain 124, 1777-1790.

Rodriguez-Oroz MC, Zamarbide I, Guridi J, Palmero MR, \& Obeso JA (2004). Efficacy of deep brain stimulation of the subthalamic nucleus in Parkinson's disease 4 years after surgery: double blind and open label evaluation. J Neurol Neurosurg Psychiatry 75, 1382-1385.

Schaltenbrand G \& Bailey P (1959). Introduction to stereotaxis with an atlas of the human brain, Vol 2 Stuttgart: Thiene.

Slavin KV \& Burchiel KJ (2002). MicroGuide microelectrode recording system. Neurosurgery 51, 275-278.

Sterio D, Zonenshayn M, Mogilner AY, Rezai AR, Kiprovski K, Kelly PJ, \& Beric A (2002). Neurophysiological refinement of subthalamic nucleus targeting. Neurosurgery 50, 58-67.

Talairach J, David M, Tournoux P, Corredor H, \& Kvasina T (1957). Atlas d'anatomie stéréotaxique. Repérage radiologique indirect des noyaux gris centraux des régions mesencéphalo sous-optique et hypothalamique de l'homme. Masson et Cie, Paris.

Theodosopoulos PV, Marks WJ, Jr., Christine C, \& Starr PA (2003). Locations of movementrelated cells in the human subthalamic nucleus in Parkinson's disease. Mov Disord 18, 791-798. 
Table 1: Electrophysiological characteristics of ZI, STN and SN neurons, revealed during indirect, atlas-based, probabilistic targeting of the STN.

Firing rate

Authors
Mean \pm SD

Year $\mathbf{n}$ [min ; max]

$(\mathrm{Hz})$
Activity

irregular regular tonic rhythmic

mov. background
related

\begin{tabular}{|c|c|c|c|c|c|c|c|c|}
\hline ZI & & & & & & & & \\
\hline Merello M. et al. & 2006 & 12 & $29.5 \pm 22$ & & & & & - (low) \\
\hline \multicolumn{9}{|l|}{ STN } \\
\hline Hutchison W. R. et al. & 1998 & & $37 \pm 17$ & - & & & & \\
\hline Magnin M. et al. & 2000 & 29 & $41 \pm 21$ & & a & & & \\
\hline Magarinos-Ascone C. M. et al. & 2000 & 12 & {$[59 ; 69]$} & & & घ & घ & \\
\hline Bejjani B.-P. et al. & 2000 & 12 & $39 \pm 24$ & - & & & & \\
\hline Levy R. et al. & 2000 & 9 & 46 & & & & घ & \\
\hline Rodriguez-Oroz M. C. et al. & 2001 & 14 & $33 \pm 17$ & a & & & & \\
\hline Sterio D. et al. & 2002 & 26 & $47 \pm 12$ & & & & & घ (high) \\
\hline Benazzouz A. et al. & 2002 & 153 & $42 \pm 22$ & ! & & & - & \\
\hline Theodosopoulos P. V. et al. & 2003 & 34 & $34 \pm 14$ & & & & - & \\
\hline Montgomery E. B. Jr & 2007 & 9 & $8 \pm 7$ & & & & & \\
\hline \multicolumn{9}{|l|}{ SN } \\
\hline Hutchison W. R. et al. & 1998 & & $71 \pm 23$ & & घ & & & \\
\hline Rodriguez-Oroz M. C. et al. & 2001 & 14 & $72 \pm 28$ & & & घ & & \\
\hline Sterio D. et al. & 2002 & 26 & $71 \pm 23$ & & - & & & \\
\hline Benazzouz A. et al. & 2002 & 153 & $30 \pm 13$ & & & - & & \\
\hline Theodosopoulos P. V. et al. & 2003 & 34 & $86 \pm 16$ & & & & & \\
\hline Galati S. et al. & 2006 & 10 & $65 \pm 23$ & & & & & \\
\hline Maltete D. et al. & 2007 & 8 & $35 \pm 14$ & & ! & & & \\
\hline
\end{tabular}

Mean firing rate, pattern of neuronal activity characterized by irregular, regular, tonic and rhythmic discharge, modulation of the cell discharge during passive movement, low or high amplitude of background activity (base noise), were resumed for ZI, STN and SN recorded in several studies ( $\mathrm{n}$, number of patients) 
Table 2: Electrophysiological parameters (mean firing rate, burst frequency and pattern rates) in the most frequently explored structures ZI, field of Forel H2, STN and SN (difference structure minus neighbours and comparison between structures).

\begin{tabular}{|c|c|c|c|c|c|c|c|c|c|c|c|}
\hline \multirow{3}{*}{$\begin{array}{l}\text { Electrophysiologic } \\
\text { parameters }\end{array}$} & \multirow[b]{3}{*}{ Structure } & \multirow[b]{3}{*}{$\mathrm{n}$} & \multicolumn{3}{|c|}{$\begin{array}{c}\text { Difference } \\
\text { Structure-Neighbours }\end{array}$} & \multicolumn{6}{|c|}{ Comparison between structures } \\
\hline & & & \multicolumn{3}{|c|}{ signed-ranks test } & \multicolumn{6}{|c|}{$\begin{array}{l}\text { global F-test: } \mathrm{F}(\mathrm{n}, \mathrm{d}) \text {, } \\
\text { followed by pairwise comparisons (pwc) }\end{array}$} \\
\hline & & & Mean & $\pm \mathrm{SD}$ & $p$ & Mean & $\pm \mathrm{SD}$ & $\mathrm{F}(\mathrm{n}, \mathrm{d})$ & $p$ & \multicolumn{2}{|c|}{ pwc } \\
\hline \multirow{4}{*}{ Mean firing rate } & $\overline{\mathrm{ZI}}$ & 10 & -6.03 & 14.1 & 0.28 & 14.49 & 18.25 & \multirow{4}{*}{$\begin{array}{c}2.13 \\
(3,24)\end{array}$} & \multirow{4}{*}{0.12} & & \\
\hline & $\mathrm{H} 2$ & 8 & -5.45 & 7.02 & 0.08 & 9.55 & 9.94 & & & & \\
\hline & STN & 10 & 2.33 & 8.08 & 0.32 & 20.20 & 16.01 & & & & \\
\hline & $\mathrm{SN}$ & 9 & 8.26 & 10.4 & $\underline{0.05}$ & 28.43 & 18.92 & & & & \\
\hline \multirow{4}{*}{ Burst frequency } & ZI & 10 & -0.31 & 0.45 & $\underline{0.02}$ & 23.16 & 39.60 & \multirow{4}{*}{$\begin{array}{c}3.13 \\
(3,24)\end{array}$} & \multirow{4}{*}{0.04} & \multirow{4}{*}{\multicolumn{2}{|c|}{+}} \\
\hline & $\mathrm{H} 2$ & 8 & -0.32 & 0.14 & $\underline{0.01}$ & 9.84 & 10.20 & & & & \\
\hline & STN & 10 & 0.05 & 0.38 & $\overline{0.92}$ & 39.84 & 37.80 & & & & \\
\hline & $\mathrm{SN}$ & 9 & 0.44 & 0.52 & 0.07 & 65.16 & 55.20 & & & & \\
\hline \multirow{4}{*}{1} & ZI & 10 & -0.06 & 0.16 & 0.30 & 0.27 & 0.19 & \multirow{4}{*}{$\begin{array}{c}0.12 \\
(3,26)\end{array}$} & \multirow{4}{*}{0.95} & & \\
\hline & $\mathrm{H} 2$ & 9 & -0.03 & 0.21 & 0.55 & 0.30 & 0.24 & & & & \\
\hline & STN & 10 & -0.08 & 0.28 & 0.50 & 0.25 & 0.19 & & & & \\
\hline & SN & 10 & -0.09 & 0.16 & 0.20 & 0.25 & 0.16 & & & & \\
\hline \multirow{4}{*}{$2 \mathrm{~A}$} & ZI & 10 & -0.03 & 0.20 & 0.49 & 0.25 & 0.20 & \multirow{4}{*}{$\begin{array}{c}0.33 \\
(3,26)\end{array}$} & \multirow{4}{*}{0.80} & & \\
\hline & $\mathrm{H} 2$ & 9 & 0.07 & 0.29 & 0.57 & 0.35 & 0.34 & & & & \\
\hline & STN & 10 & 0.00 & 0.10 & 1.00 & 0.28 & 0.14 & & & & \\
\hline & SN & 10 & 0.02 & 0.20 & 0.85 & 0.32 & 0.20 & & & & \\
\hline \multirow{4}{*}{$2 B$} & ZI & 10 & 0.05 & 0.28 & 0.82 & 0.29 & 0.28 & \multirow{4}{*}{$\begin{array}{c}0.38 \\
(3,26)\end{array}$} & \multirow{4}{*}{0.77} & \multirow{12}{*}{$\#$} & \\
\hline & $\mathrm{H} 2$ & 9 & -0.03 & 0.22 & 0.82 & 0.19 & 0.25 & & & & \\
\hline & STN & 10 & -0.03 & 0.12 & 0.49 & 0.23 & 0.14 & & & & \\
\hline & $\mathrm{SN}$ & 10 & 0.05 & 0.16 & 0.38 & 0.27 & 0.21 & & & & \\
\hline \multirow{4}{*}{$2 \mathrm{C}$} & ZI & 10 & -0.11 & 0.15 & $\underline{0.04}$ & 0.11 & 0.15 & \multirow{4}{*}{$\begin{array}{c}4.99 \\
(3,26)\end{array}$} & \multirow{4}{*}{0.007} & & \\
\hline & $\mathrm{H} 2$ & 9 & -0.15 & 0.14 & $\underline{0.03}$ & 0.06 & 0.08 & & & & \pm \\
\hline & STN & 10 & 0.11 & 0.31 & $\overline{0.38}$ & 0.29 & 0.27 & & & & 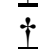 \\
\hline & SN & 10 & 0.09 & 0.15 & 0.08 & 0.32 & 0.15 & & & & \\
\hline & ZI & 10 & -0.00 & 0.08 & 0.50 & 0.05 & 0.07 & & & & \\
\hline 4 & $\mathrm{H} 2$ & 9 & -0.04 & 0.07 & 0.11 & 0.02 & 0.03 & 1.51 & & & \\
\hline 4 & STN & 10 & 0.01 & 0.12 & 0.65 & 0.07 & 0.10 & $(3,26)$ & 0.24 & & \\
\hline & $\mathrm{SN}$ & 10 & 0.04 & 0.03 & 0.43 & 0.10 & 0.11 & & & & \\
\hline
\end{tabular}


Left panel: paired means comparison between the structure and the structure's neighbours. Means, SD and $p$ value were calculated from $n$ patients. Analysis carried-out testing towards 0 the mean difference between these two measures (structure value minus neighbour value) through a signed-ranks test. Right panel: for each electrophysiological parameter (Mean, SD from $n$ patients), structure values were compared between structures through mixed linear regression (F(numerator, denominator) and p-value) and, when appropriate, all pairwise differences were tested with adjusted $\mathrm{p}$-values (pwc $+: p=0.04$; $\#$ : $p=0.02 ; \dagger: p=0.04$ ). 
A.

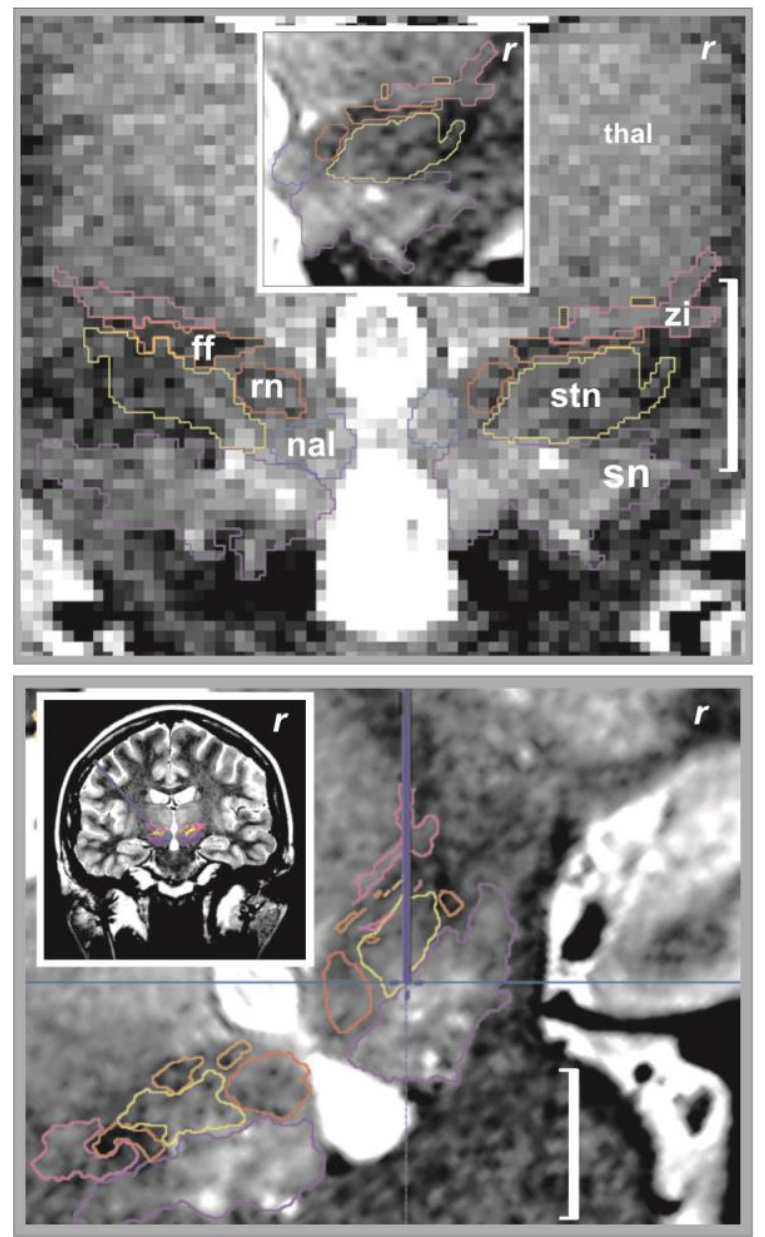

B.

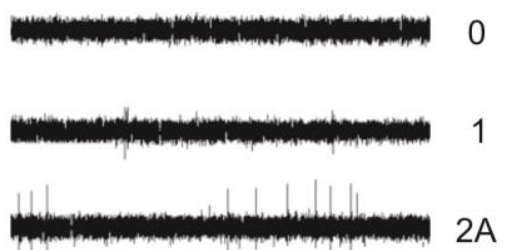

Figure 1. A. Example of stereotactic MRI anatomic mapping and primary targeting ( $r$, right hemisphere, white bar $=1 \mathrm{~cm})$ : (top) anatomic mapping (label + outline) on a coronal $\mathrm{T} 2$ weighted slice (raw image), thalamus (thal), substantia nigra (sn), subthalamic nucleus (stn), zona incerta (zi), fields of Forel (ff), nucleus of the ansa lenticularis (nal) and red nucleus (rn), inlet, close-up on the interpolated image; (bottom) primary anatomic targeting, reconstructed and interpolated pseudo-coronal slice along the right central track (blue line), inlet, 3D view of the right trajectory. B. Pattern types of neuronal activity (x-axis, 3 -sec window), $0=$ background noise, 1 = isolated activity, $2 \mathrm{~A}=$ irregular low activity, $2 \mathrm{~B}=$ irregular moderate activity, $2 \mathrm{C}=$ irregular high activity, 3 = low burst activity, 4 = high burst activity, $5=$ rhythmic activity, and 6 $=$ permanent tonic activity. 
A.
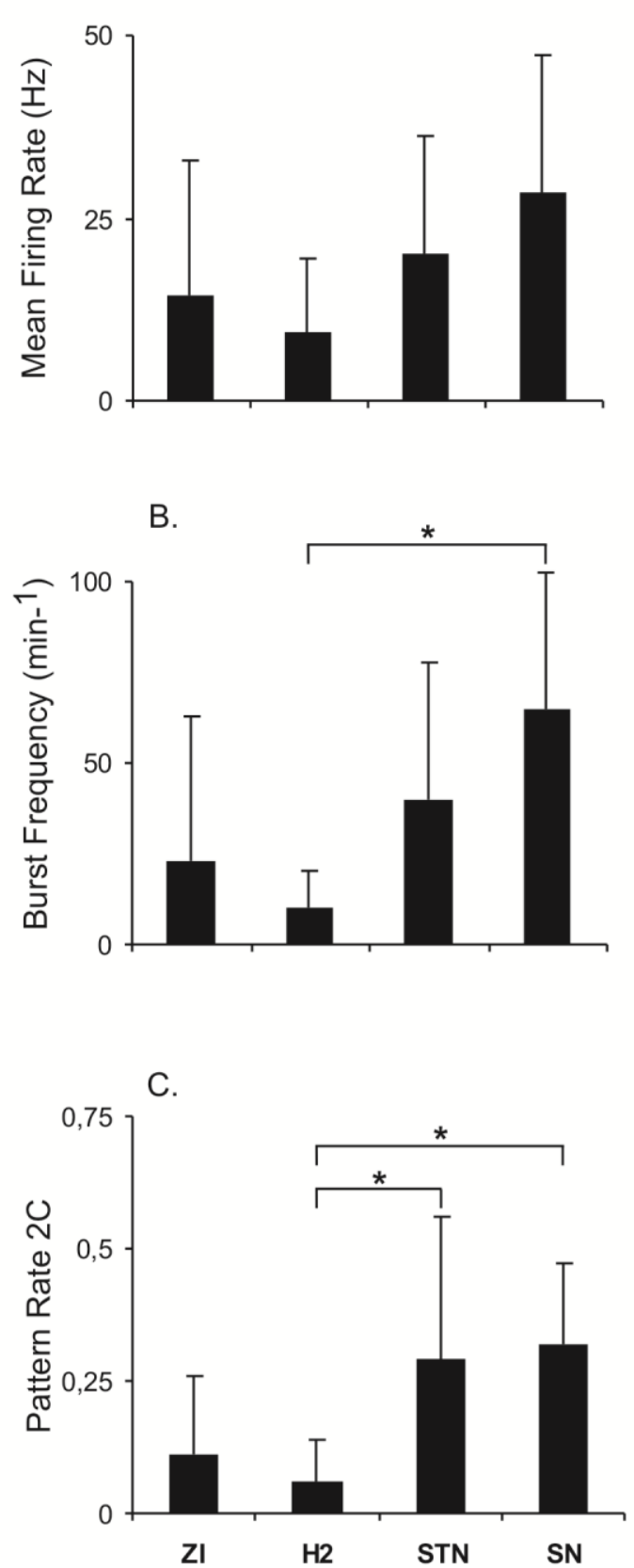

Figure 2. Relationship between MRI anatomic structures (most frequently explored) and electrophysiological parameters: A. mean firing rate, B. frequency of burst occurrences and C. irregular high activity pattern rate $(*$ : significant pairwise comparison test, adjusted $\mathrm{p}<0.05)$. 


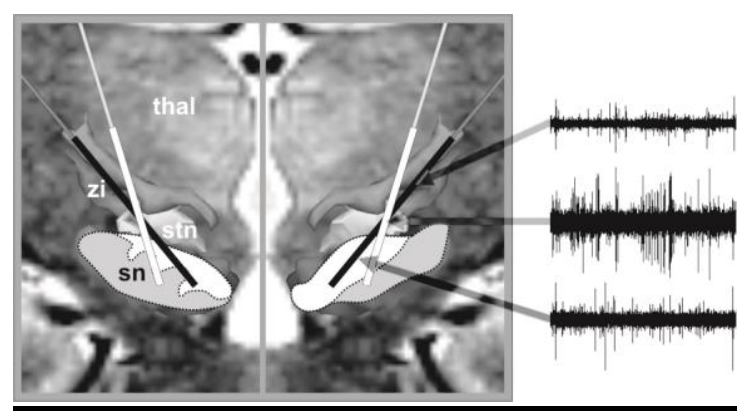

Figure 3: Semi-schematic representation (on a real case) of intended trajectories planned based on our direct patient-by-patient anatomic mapping (black line) and based on a classic probabilistic atlas approach (white line; see example in Bejjani et al., 2000 or Sterio et al., 2002). Thalamus (thal) and subthalamic nuclei, i.e. zona incerta (zi), subthalamic nucleus (stn) and subtantia nigra (sn). The pars compacta (white) and pars reticulata (grey) of the subtantia nigra are represented (manual registration) according to Parent (1996) (left) and Schaltenbrand \& Bailey (1959) (right). Example of neuronal activities recorded within ZI, STN and SN. 